\title{
Salivary duct stenosis: diagnosis and treatment
}

\author{
Stenosi duttali salivari: diagnosi e terapia \\ M. KOCH, H. IRO \\ Department of Otorhinolaryngology, Head and Neck Surgery, Friedrich Alexander University of Erlangen, \\ Nuremberg, Germany
}

\begin{abstract}
SUMMARY
The management of stenoses of the major salivary glands had undergone a significant change during the last 15-20 years. Accurate diagnosis forms the basis of adapted minimal invasive therapy. Conventional sialography and MR-sialography are useful examination tools, and ultrasound seems to be a first-line investigational tool if salivary duct stenosis is suspected as cause of gland obstruction. Sialendoscopy is the best choice to establish final diagnosis and characterise the stenosis in order to plan accurate treatment. In all major salivary glands, inflammatory stenosis can be distinguished from fibrotic stenosis. In the parotid duct system, an additional stenosis associated with various abnormalities of the duct system has been reported. Conservative therapy is not sufficient in the majority of cases. The development of a minimally invasive treatment regime, in which sialendoscopy plays a major role, has made the preservation of the gland and its function possible in over $90 \%$ of cases. Ductal incision procedures are the most important measure in submandibular duct stenoses, but sialendoscopy becomes more important in the more centrally located stenoses. Sialendoscopic controlled opening and dilation is the dominating method in parotid duct stenoses. In 10-15\% of cases, success can be achieved after a combined treatment regime had been applied. This review article aims to give an overview on the epidemiology, diagnostics and current state of the art of the treatment of salivary duct stenoses.
\end{abstract}

KEY WORDS: Salivary duct stenosis $\bullet$ Treatment $\bullet$ Sialendoscopy $\bullet$ Minimal invasive $\bullet$ Gland preservation

\section{RIASSUNTO}

La gestione delle stenosi delle ghiandole salivari maggiori ha subito un cambiamento significativo nel corso degli ultimi 15-20 anni. L'elemento fondamentale che sta alla base di una scelta terapeutica minimamente invasiva è rappresentato da un'accurata diagnosi. La scialografia convenzionale e la scialo-RM possono essere utili strumenti per la diagnosi delle stenosi salivare, senza dimenticare il ruolo basilare e centrale dell'ecografia qualora si sospetti che un processo stenotico a carico dei dotti salivari sia la causa dell'ostruzione. Tuttavia, ad oggi, la scialoendoscopia rappresenta la scelta diagnostica migliore, permettendo una corretta pianificazione terapeutica attraverso una quanto più precisa caratterizzazione della stenosi. Sia a livello sottomandibolare che parotideo è possibile distinguere le stenosi infiammatorie da quelle secondarie a processi fibrotici e, inoltre, a carico dei dotti salivari parotidei è stata descritta una stenosi associata a varie anomalie del sistema duttale. Nella maggior parte dei casi la sola terapia conservativa non è sufficiente per la risoluzione della sintomatologia ostruttiva, tuttavia lo sviluppo di trattamenti minimamente invasivi, prima fra tutte la scialoendoscopia, ha permesso di ottenere un tasso di conservazione della funzione ghiandolare di oltre il $90 \%$ dei casi. Se a livello sottomandibolare la principale misura terapeutica nella gestione delle stenosi del dotto ghiandolare rimane l'incisione duttale (eccezion fatta per il crescente ruolo della scialoendoscopia nelle stenosi centrali), viceversa a livello del dotto parotideo la stenosi viene preminentemente gestita mediante la scialoendoscopia. Va comunque sottolineato che nel 10-15\% dei casi il successo terapeutico viene ottenuto attraverso un trattamento di tipo combinato. La seguente review si propone di fornire una panoramica circa l'epidemiologia, la diagnostica e l'attuale stato dell'arte del trattamento delle stenosi salivari.

PAROLE CHIAVE: Stenosi duttali salivari $\bullet$ Terapia $\bullet$ Scialoendoscopia $\bullet$ Minimamente invasiva $\bullet$ Preservazione della funzione ghiandolare

Acta Otorhinolaryngol Ital 2017;37:132-141

\section{Introduction}

The symptoms of obstructive diseases of the salivary glands consist of recurrent painful swelling of the major salivary glands, especially after food intake. This often leads to a marked reduction of the patient's quality of life. Salivary duct stenoses are a relatively rare pathological condition and are often diagnosed in specialised centres. The management of these conditions has changed dramatically during the last 10-20 years. This article aims to provide an overview of recent developments in this field.

\section{Epidemiology and diagnosis}

Salivary duct stenoses are the second most frequent cause of obstructions in the salivary glands, representing 15$25 \%$ of cases in the parotid gland and $5-10 \%$ of all obstructions of the submandibular gland ${ }^{1-7}$. Up to $50 \%$ in cases of unclear gland swelling and up to $85 \%$ in cases of obstruction are not caused by sialolithiasis ${ }^{3-589}$.

Around $70-75 \%$ of stenoses are located in the parotid and $25-30 \%$ in the submandibular duct system ${ }^{45}$. Stenoses are associated with sialolithiasis in over $15 \%$ of cases in the parotid gland and in $2-5 \%$ of cases in the submandibular 
gland ${ }^{3-59-11}$. Typically, stenoses in both glands are associated with chronic inflammatory changes in the ductal system and parenchyma. Reduced salivary flow, ascending duct infection and the formation of mucous or fibrinous plaques and strictures or stenoses are the consequence ${ }^{1710} 10^{12-17}$.

Particularly in the submandibular gland, the clinical picture of chronic recurrent inflammation is poorly defined. After sialendoscopy examinations in 467 glands, Yu et al. found that stenosis was the cause in $6 \%$ of cases ${ }^{6}$. Koch et al. and Kopec et al. investigated possible causes and/ or associated diseases in Wharton's duct stenosis. Allergy (up to $26.8 \%$ ), autoimmune diseases (up to 16.7\%), status after irradiation $(5.1 \%)$, fibrosis due to a dental prosthesis $(1.4 \%)$ and other rare diseases $(0.7 \%)$ were described. Sialolithiasis was associated with the stenosis in up to $16.7 \%$ of cases. Status after prior surgery (with or without sialolithiasis) was noted in up to $13.8 \%$ of cases ${ }^{1014}$.

Chronic (recurrent) parotitis may be a major cause of stenoses of Stensen's duct ${ }^{712} 1718$. After analysing sialendoscopy examinations in 85 glands, Chuangqi et al. found that stenosis was the main cause of obstruction in $75 \%$ of cases ${ }^{8}$. Accompanying conditions/diseases that have been described include allergic, granulomatous and autoimmune conditions, status after radiation therapy, presence of a ductal system with anatomic variations/abnormalities, situation after trauma, disturbances of the craniomandibular system, and, rarely, chronic juvenile parotitis or IgG4-associated disease 12-15 19-21. Some authors have reported isolated obstructive gland disease characterised by fibrinous plaques and marked eosinophilic reaction without allergic or autoimmune disease ${ }^{32022}$. According to Koch et al. and Kopec et al., possible associations of stenosis with conditions and/or diseases are allergic diseases (up to 29.6\%), autoimmune diseases (up to 18.5\%), status after irradiation (up to $3.7 \%$ ) and bruxism or craniomandibular disorders (up to 5.2\%). Sialolithiasis and status after stone treatment was associated with stenoses in more than $20 \%$ of cases. In 5.2-12.9\% of cases, prior surgery of the gland or the duct system was reported 1314 .

\section{Diagnosis and classification}

Ultrasound, magnetic resonance (MR) sialography, and conventional sialography are the imaging tools most often used for diagnosis, and can all contribute to more precise characterisation of stenoses ${ }^{3423} 24$.

Strictures of the efferent ducts are diagnosed with high sensitivity with sialography using contrast medium indicating filling defects or loss of contrast in the ductal system ${ }^{4}$. Due to the use of contrast medium and application of irradiation, sialography is not first choice.

MR sialography is an alternative method of imaging stenoses that does not require the use of contrast media. Stimulation with citric acid can enhance duct obstruction and indicate the state of gland function ${ }^{23-26}$.
Ultrasound provides an overview of the entire ductal system. In both duct systems, a hypoechoic band is seen as evidence of dilation of the ductal system. The accuracy of can be significantly improved by stimulating glandular secretion using vitamin $\mathrm{C}$ administration, allowing approximate localisation of the stenosis ${ }^{35} 1327$.

Through sialendoscopy direct visualisation of the ductal system is possible, allowing establishment of the diagnosis and precise characterisation of the stenosis 1351113202128 . Qi et al. have described inflammatory changes in the duct wall that may represent a possible precursor stage to stenosis and plaques or "fibre-like substances", which are also suspected to be obstructive factors ${ }^{20}$. In general in all major salivary glands, stenosis characterised by inflammatory changes can be distinguished from fibrotic stenosis 51011132021 .

Several publications have presented various classifications of ductal stenoses. Ngu et al. analysed the numbers and locations of salivary duct stenoses in more than 1300 sialography examinations ${ }^{4}$. In $33.3 \%$ multiple and in $7 \%$ bilateral stenoses were observed. Wharton's duct strictures were found most often in the posterior third including the hilar region (68.2\%), in Stensen's duct the middle third $(39.6 \%)$ and the proximal third $(37.8 \%)$ were most often involved ${ }^{4}$.

No ssialendoscopy-based classification had been published concerning stenoses of submandibular duct stenoses. In one report by our own research group these stenoses were described more detailed ${ }^{10}$.

After sialendoscopy in 153 Wharton's duct stenoses reported by Koch et al., fibrous stenoses were present in $87.3 \% ; 62.7 \%$ were at the papilla or in the distal duct, but only $18.3 \%$ in the proximal segment including the hilar or posthilar area, and $7.8 \%$ showed a diffuse extension pattern. Bilateral stenoses and multiple stenoses were found in $8.6 \%$ and $3 \%$, respectively ${ }^{10}$. Similar results were reported by others ${ }^{14}$. Compared to the publication of Ngu et al. ${ }^{4}$, the distribution of locations was reversed. Multiple stenoses were observed more frequently in this study ( $48.5 \%$ vs. $3 \%$ ), but no bilateral stenoses were encountered, compared to $8.6 \%$ in the study by Koch et al. ${ }^{410}$. Previous surgery in the area of the ductal system may have contributed to these differences.

Several sialendoscopy-based classifications of stenoses of the parotid duct system have been published by Marchal et al. ${ }^{29}$ and our own research group ${ }^{11}{ }^{21}$. Marchal et al. proposed a classification based on lithiasis, stenosis and dilation ("LSD" classification), which takes into account the site, number and severity of stenoses. However, the study does not offer any patient numbers to substantiate this ${ }^{29}$. Koch et al. published a first classification describing all changes in the ductal system that were visible with the sialendoscope in 111 stenoses $^{21}$, which was extended and specified in a subsequent publication including 550 stenoses ${ }^{11}$. Different sialendoscopes were used to clas- 
sify the stenoses in accordance with various criteria: the location of the stenosis in the ductal system, length of the stenosis, grade of luminal narrowing, number, site and laterality and tissue quality within the stenotic area. Depending on the appearance of the tissue in the stenotic region, three main types were distinguished. Type 1 stenosis was characterised by inflammatory changes in the stenotic area (8.9\%), type 2 stenoses were associated with an abnormal duct system that showed circular or web-like changes and megaduct (19.5\%) and type 3 stenoses were characterised by purely fibrotic reactions, with diffuse involvement of the duct wall (71.6\%). Multiple stenoses were found in $2.8 \%$ and bilateral stenoses in $11.9 \%$ of cases. Two-thirds were located in the distal or middle duct system. Over $95 \%$ were middle two high-grade stenoses. Nearly $80 \%$ were short, but $8.9 \%$ were diffuse. Kopec et al. published similar results after analysing 27 stenoses ${ }^{14}$. Type 1 stenoses differed significantly from type 3 stenoses, with lower grades. Type 3 stenoses showed significantly higher grades of luminal narrowing than the other two types. Type 2 stenoses were significantly shorter in comparison with the other two types. Multiple stenoses were observed significantly more often in type 2 than in type 3 stenoses ${ }^{1121}$. Type 1 stenosis may be a precursor form of type 3 stenosis that can be diagnosed simultaneously in the same ductal system ${ }^{11}$. By contrast, type 2 stenoses occur in obviously variant ductal systems that usually have - in addition to a variable number of stenoses - typical abnormalities (webs/encroachments, duct bending/kinks, megaduct with very thin duct wall) along the entire length. However, most of these webs or encroachments do not form a relevant stenosis, although they may appear as strictures/stenoses on radiological examinations (e.g., sialography). These results appear to indicate that type 2 stenosis is completely different in comparison with the other types and has a different, but not fully understood, underlying pathogenesis. A few publications have described similar situations when reporting patients presenting with "sialectasis" or "sialoceles" of the parotid duct ${ }^{30-36}$.

\section{Treatment}

In general, symptom-free stenoses and stenoses associated with recognisable atrophy of the gland require no treatment, or only exclusively conservative treatment. This includes gland massage, anti-inflammatory treatment and antibiotic treatment if necessary. Treatment provided for salivary duct stenoses has changed dramatically during the last 20 years. The development of minimally invasive treatment regimens has led to a significant reduction in the rate of gland resection. In the era before minimally invasive therapy, the failure rate after conservative treatment was nearly $50 \%$, and gland resection was the next step in many of these cases ${ }^{12}{ }^{18}$. This changed after the develop- ment of minimally invasive treatment options, involving various methods of transoral ductal surgery, radiologically-guided methods and sialendoscopy-guided therapy. However, it should be emphasised that one of the essential prerequisites for any successful treatment, independently of the method chosen, appears to be an adequate gland function. If an impaired gland is not recovering, the use of almost any approach may not be successful ${ }^{37-40}$.

\section{Sialography-guided balloon dilation}

In the early years after sialendoscopy was introduced into clinical medicine, sialography-guided balloon dilation was carried out, with substantial success rates ${ }^{41}{ }^{42}$. Although (partial or complete) opening of duct stenoses was regularly reported in more than $80 \%$ of cases, no detailed information regarding follow-up (state of complaints, gland preservation rate) was provided in most reports ${ }^{41} 4348$. Drage et al. described 36 cases after sialographically-guided therapy (the glands were not specified). It was possible to dilate the stenoses in $92 \%$ of cases, and post-interventional sialographic control showed complete opening in $82 \%$ and partial opening in $14 \%$ of cases. Follow-up sialography after various time intervals showed complete opening in $48 \%$, partial opening in 5\% and an unchanged situation (recurrent stenosis) in 33\% of cases with follow-up. No complaints and partially improved symptoms were noted in $48 \%$ each ${ }^{47}$. Salerno et al. reported on nine cases (seven parotid, two submandibular glands). Moderate to good opening was possible in $88.9 \%$ of cases (six parotid, two submandibular glands). A completely symptom-free state was achieved in $77.8 \%$ (five parotid and two submandibular glands) ${ }^{48}$. A summary of the results is shown in Table I. Although acceptable results were achieved with sialography-guided balloon dilation, it has the disadvantage that it only allows indirect visualisation of the stenosis, involves radiation exposure and is associated with a risk of reaction to contrast media. In view of the opportunities provided by sialendoscopyguided therapy, sialographic controlled treatment currently does not appear to be the treatment of choice.

The present review therefore focuses on sialendoscopyguided therapy.

Sialendoscopy-guided therapy of minimally invasive treatment regime: general aspects and the role of adjuvant and medical treatment

Regular/daily gland massage with sialogogues and repeated irrigation with cortisone are among the basic measures in the treatment sequence and aftercare. If primary therapy was carried out using sialendoscopy-guided measures, then irrigation with intraductal cortisone was often included 13913143840 49-57. A recent prospective pilot study by Capaccio et al. confirmed the value of intraductal cortisone administration. The outcomes for patients were compared 6 months after (interventional) sialendoscopy, 
Table I. Results in the literature after minimally invasive, sialographic-controlled treatment of salivary duct stenoses.

\begin{tabular}{|c|c|c|c|c|c|c|c|c|}
\hline Author (year) & $\begin{array}{l}\text { Glands } \\
\text { total } \\
\text { (n) }\end{array}$ & $\begin{array}{c}\text { SMG } \\
(n)\end{array}$ & $\begin{array}{l}P G \\
(n)\end{array}$ & $\begin{array}{l}\text { Partial } \\
\text { success of } \\
\text { procedure } \\
\text { (\% glands) }\end{array}$ & $\begin{array}{l}\text { Complete } \\
\text { success of } \\
\text { procedures } \\
\text { (\% glands) }\end{array}$ & $\begin{array}{l}\text { Improve of } \\
\text { symptoms } \\
\text { (\% patients) }\end{array}$ & $\begin{array}{c}\text { Recurrent or } \\
\text { persistent } \\
\text { complaints } \\
\text { (\% patients) }\end{array}$ & $\begin{array}{l}\text { Preservation of } \\
\text { gland } \\
(\%)\end{array}$ \\
\hline $\begin{array}{r}\text { Buckenham et al. (1992) } \\
\text { (1993) }\end{array}$ & $\begin{array}{l}1 \\
3\end{array}$ & n.n. & $\begin{array}{l}1 \\
3\end{array}$ & ---- & $\begin{array}{l}100 \\
100\end{array}$ & $\begin{array}{l}\text { n.n. } \\
\text { n.n. }\end{array}$ & $\begin{array}{l}\text { n.n. } \\
\text { n.n. }\end{array}$ & $\begin{array}{l}\text { n.n. } \\
\text { n.n. }\end{array}$ \\
\hline Roberts et al. (1995) & 3 & ---- & 3 & ----- & 100 & 100 & 33.3 & n.n. \\
\hline Brown et al. (1997) & 30 & 6 & 24 & ---- & $\begin{array}{l}\text { Total } 86.7 \\
\text { SMG } 50 \\
\text { PG } 96\end{array}$ & $\begin{array}{l}\text { Total } 77 \\
\text { SMG } 33.3 \\
\text { PG } 57\end{array}$ & $\begin{array}{c}\text { Total } 30 \\
\text { SMG } 66.7 \\
\text { PG } 21.7\end{array}$ & $\begin{array}{c}\text { Total } 93.3 \\
\text { SMG } 33.3 \\
\text { PG } 100\end{array}$ \\
\hline Waldmann et al. (1998) & 1 & ---- & 1 & ----- & 100 & 100 & 100 & 100 \\
\hline Drage et al. (2002) & 36 & n.n. & n.n. & 14 & 82 & 96 & 52 & n.n. \\
\hline Brown et al. (2006) & 125 & n.n. & n.n. & 9.6 & 71.5 & n.n. & n.n. & n.n. \\
\hline Salerno et al. (2007) & 9 & 2 & 7 & $\begin{array}{l}\text { Total } 55.5 \\
\text { SMG } 50 \\
\text { PG } 57.2\end{array}$ & $\begin{array}{l}\text { Total } 33.3 \\
\text { SMG } 50 \\
\text { PG } 28.6\end{array}$ & $\begin{array}{l}\text { Total } 77.8 \\
\text { SMG } 50 \\
\text { GP } 85.7\end{array}$ & $\begin{array}{l}\text { Total } 22.2 \\
\text { SMG } 50 \\
\text { GP } 14.3\end{array}$ & n.n. \\
\hline
\end{tabular}

Legend: SMG: submandibular gland, PG: parotid gland

with or without intraductal cortisone treatment in cases of unclear obstruction, including cases with stenosis. It was found that patients who received intraductal cortisone had a significantly better outcome in comparison with patients who did not have additional treatment. The authors concluded that "sialendoscopy with intraductal steroid irrigation was more effective than interventional sialendoscopy alone in the medium term" 57.

Most of the publications on this topic describe the results after treatment for stenosis in a few patients, but without any distinction between glands. Detailed data on the nature of the stenosis, success rates of the procedures and follow-up findings are not provided, and no information about symptoms or gland resection status is offered. Irrigation with cortisone is reported in nearly all publications; the instruments used are the sialendoscope itself, microdrills, baskets, various dilators, graspers and balloons. Stents were implanted in $10-100 \%$ of cases described 19144953545658 .

Sialendoscopy-guided therapy and minimally invasive treatment regimen in Wharton's duct stenoses

Treatment for submandibular stenoses has so far only been described in very few studies. Treatment procedures described included limited and extensive ductal incision procedures and interventional sialendoscopy 35104250 59-62. Nonspecific data and/or a lack of data in most publications make precise analysis and assessment of the value of sialendoscopy-guided therapy difficult. Overall success rates of the procedures were in the range of $80-100 \%$; complete resolution of symptoms was achieved in 50-80\% and gland preservation in 90-100\% of cases 15910144953545658 .

Nahlieli et al. were the first to report on the treatment of stenoses in 11 submandibular glands, with results that were not specific for submandibular glands. Balloons were used for dilation in $80 \%$ of cases, blunt obturators/ dilators in $12 \%$ and stents in $100 \%$. Eighty per cent of patients became symptom-free, symptoms improved in $16 \%$ and gland preservation was achieved in $96 \%{ }^{1}$.

Comprehensive, multimodal treatment in 153 of these stenoses has been reported in detail by Koch et al. ${ }^{10}$. Transoral duct surgery was successful in $58.1 \%$ of cases, and this proved to be the most important treatment modality in this gland. The prerequisite for ductal incision is that marsupialisation of the duct and creation of a neo-ostium is possible. Marsupialisation appears to be particularly important, as gland function is often compromised. These procedures may extend beyond the hilum to submandibulotomy as described in the treatment of sialolithiasis ${ }^{506364}$. Interventional sialendoscopy was carried out successfully in $26.8 \%$ of cases, particularly in proximal or more central posthilar stenoses. Irrigation with cortisone alone was sufficient in $12.4 \%$. Overall, $93 \%$ of patients who underwent endoscopic treatment also became free of symptoms, and sialendoscopy-based techniques played a decisive role in the treatment in $39.2 \%$ of cases. The value of intraductal endoscopy-guided treatment increased from the distal to the proximal duct system, but was limited in diffuse stenosis. The gland preservation rate was $97.8 \%$. After a mean follow-up period of more than 4 years, $3 \%$ of patients with preserved glands had relevant persistent symptoms ${ }^{10}$. In summary, the location of the stenosis is one of the most important factors for decision-making on how to treat Wharton's duct stenosis. In view of the accessibility of the submandibular duct system, various methods of transoral duct incision appear to be indicated for stenoses from the papilla to the hilum. In stenosis of the proximal ductal system and hilar region, sialendoscopy-guided opening and dilation appear to be a good treatment option to extended transoral duct slitting. Particularly in the hilar and posthilar area, and also sometimes in localised stenoses of the intraparenchymal ductal system, sialen- 
doscopy provides unique direct visualisation of a segment of the ductal system that cannot be adequately visualised with other methods.

A treatment algorithm describing all gland-preserving treatment modalities has been published (Fig. 1) ${ }^{50}$.

\section{Sialendoscopy-guided therapy and minimally invasive} treatment regimen Stensen's duct stenoses

Parotid duct stenoses are difficult to treat. Before the minimally invasive era, stenoses could not be clearly defined, and treatment for this condition was often carried out with a diagnosis of "chronic parotitis". Numerous reports on the treatment of chronic parotitis were published and the results were reported to be unsatisfactory in the majority of cases ${ }^{12} 1865$. Systemic anti-inflammatory treatment, which consists of administration of antibiotics and especially hydrocortisone, is the established first-line therapy ${ }^{126566}$. Local treatment, such as irrigation of the duct with contrast medium or saline solution and intraductal application of medicaments was also reported ${ }^{67-69}$. This form of treatment does not lead to cure and is not successful in up to 40-50\% of cases, making further therapy necessary ${ }^{12} 1865$. More invasive methods used are various surgical procedures in the distal duct system, such as (extended) papillotomy, distal duct incision, sialodochoplasty with duct reinsertion or duct ligation. High failure rates, ranging from $50 \%$ to $70 \%$, have been described 1218 6570-72. Consequently, up to the early 2000s, parotidectomy was still thought to be unavoidable in the course of the disease in over $40 \%$ of cases ${ }^{12} 656673-77$. The introduction of sialendoscopy made it possible to diagnose parotid duct stenosis in cases with chronic parotitis. Few publications dealing with sialendoscopy-based treatment reporting data concerning short to medium-term follow-up periods have been reported. Most of the studies only include relatively few patients, and glands are not differentiated. In addition, detailed data regarding the nature of the stenosis, the success rates of the procedures and follow-up data specific for the gland are not provided. The success rates of procedures were over $80-100 \%$, with complete success reported in 70-90\% and gland preservation in 90-100\% 13913143849 51-5678.

Nahlieli et al. first published results on treatment of 25 stenoses, 14 of which were parotid stenosis, but the glands were not differentiated regarding treatment results (details see above and Table II) ${ }^{1}$.

Ardekian et al. treated 87 parotid duct stenoses. Irrigation with cortisone and application of hydrostatic pressure were performed in all cases. The stenoses were opened and dilated with sialo-balloons, and forced manipulation using a microdrill was described in very difficult cases. Stents were implanted in nine cases, and administration of cortisone and antibiotics (penicillin) in the ductal system was also performed. The results showed that the procedure was successful in $81.7 \%$ of glands, and failures were noted in $4.6 \%$ of cases ${ }^{51}$.

Vashishta and Gillespie treated a total of 51 patients with unclear swelling of the major salivary glands (but the glands are not specified). Ninety-two per cent of the patients $(47 / 51)$ had stenoses $(59 \%)$ or strictures $(33 \%)$. Microdrills and dilators were used in $78 \%$, stent implantation was performed in $10 \%$ and botulinum toxin was injected in $8 \%$. No specific data were provided about the success rate after sialendoscopy for stenoses. Overall, $61 \%$ of patients became completely symptom-free and $27 \%$ experienced improvement. Gland resection was performed in $4.2 \%{ }^{9}$.

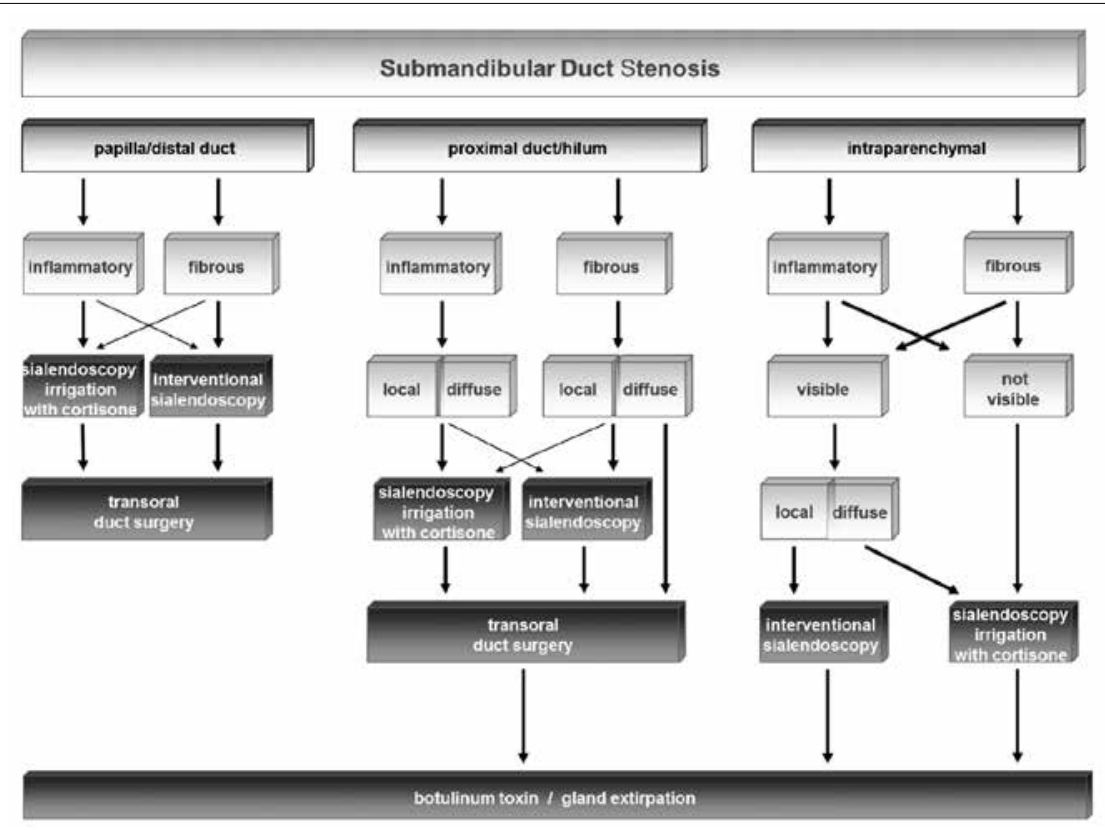

Fig. 1. Treatment algorithm for stenoses in Wharton's duct system (from Koch et al., $2009{ }^{50}$, mod.). 
After reporting on the preliminary results in 39 patients ${ }^{13}$, Koch et al. presented another study on 93 patients with 111 stenoses in 99 glands, also taking into account the differences observed in parotid duct stenoses ${ }^{52}$. Interventional sialendoscopy proved to be the most important treatment modality, with successful results in $59.2 \%$ of cases. Irrigation with cortisone and application of hydrostatic pressure was the only treatment administered in $21.5 \%$ of patients. Transoral duct surgery had to be performed in combination with sialendoscopy in $8.6 \%$ of patients. Marked differences were noted when treatments for the different types of stenosis were analysed. With type 1 stenoses, irrigation with cortisone was performed in $66.7 \%$ of cases and was sufficient in $60 \%$; interventional sialendoscopy was performed in $33.3 \%$ and was successful in $26.7 \%$ of the stenoses. In type 2 stenoses, irrigation with cortisone was successful in all $47.1 \%$ cases in which it was attempted; interventional sialendoscopy was carried out in $52.9 \%$ of cases and was successful in $47.1 \%$. In type 3 , stenoses irrigation with cortisone was sufficient in only $4.9 \%$ of the cases, but interventional sialendoscopy was performed in $77.1 \%$ and was successful in $70.5 \%$ of stenoses. In these stenoses, a combination with transoral duct surgery was necessary in $18 \%$ and successful in $72.3 \%$ of these. Stent implantation was required in $63.6 \%$ of these cases, leading to a substantial reduction in the risk of recurrent stenosis, with better results than those published in the literature ${ }^{1265707275}$. In $95.1 \%$ of type 3 stenoses, minimally invasive surgical measures had to be performed. Altogether, dilation of the stenoses using interventional sialendoscopy was successful in $88.2 \%$ of all cases in which it was attempted, and stents were placed in $8.6 \%$. Gland preservation was achieved in $96.8 \%$. After nearly 2.5 years of follow-up, improvement or freedom from symptoms was achieved in
92.3\% of patients with preserved glands. The hypothesis that type 1 stenosis is a precursor form of type 3 stenosis and is thus "non-fibrous" or "nonfixed" - so that it may be reversible after treatment using anti-inflammatory and non-interventional measures - may explain the fact that any "fixed" fibrous type 3 stenosis is much more likely to require more invasive treatment measures. The specific characteristics of type 2 stenoses (> 95\% short, nearly $70 \%$ low-grade) may explain why they can be treated in a more conservative and non-invasive manner in nearly half of cases. Irrigation and gland massage may be sufficient to wash out obstructing plaques. This may be particularly important in view of the weak excretory function in these ducts. If dilation with interventional sialendoscopy is necessary, stent implantation may be part of treatment ${ }^{1152}$. A review of the literature shows that some authors have reported on the treatment of stenoses with sialectasis in the ductal system that appear to show similarities to the type 2 stenoses described by our own group. If treatment was prescribed, it consisted of various methods of transoral duct surgery including duct ligation ${ }^{30-36}$.

Combined endoscopic and transcutaneous surgery, if necessary with duct reconstruction using a vein patch or replacement with a vein graft, has been described in a few publications. This surgery was performed in single cases in all reports. The results in terms of preservation of the gland and gland function have not been sufficient to recommend the procedure ${ }^{37-39}$ as part of a standard therapy regime, but it may be a treatment option to avoid gland resection in single cases.

The only study that has reported the results after long-term follow-up was published by Koch et al. ${ }^{40}$. Reassessment was possible in $88.2 \%$ of previously treated patients ${ }^{52}$ after an average follow-up period of 98 months. Gland preser-

Table II. Results in the literature after treatment of salivary duct stenoses with a minimally invasive, sialendoscopy-dominated therapy regime.

\begin{tabular}{|c|c|c|c|c|c|c|c|}
\hline Author (year) & $\begin{array}{l}\text { Glands } \\
\text { total } \\
\text { (n) }\end{array}$ & $\begin{array}{c}\text { SMG } \\
\text { (n) }\end{array}$ & $\begin{array}{l}P G \\
\text { (n) }\end{array}$ & $\begin{array}{l}\text { Success of } \\
\text { procedures } \\
(\% \text { glands) }\end{array}$ & $\begin{array}{l}\text { Improve of } \\
\text { symptoms } \\
\text { (\% patients) }\end{array}$ & $\begin{array}{l}\text { Persistent } \\
\text { complaints } \\
\text { (\% patients) }\end{array}$ & $\begin{array}{l}\text { Preservation of } \\
\text { gland } \\
(\%)\end{array}$ \\
\hline Nahlieli et al. (2001) & 25 & 11 & 14 & $\begin{array}{l}\text { Total } 80 \\
\text { SMG n.n. } \\
\text { PG n.n. }\end{array}$ & $\begin{array}{l}\text { Total } 96 \\
\text { SMG n.n. } \\
\text { PG n.n. }\end{array}$ & $\begin{array}{l}\text { Total } 20 \\
\text { SMG n.n. } \\
\text { PG n.n. }\end{array}$ & $\begin{array}{l}\text { Total } 96 \\
\text { SMG n.n. } \\
\text { PG n.n. }\end{array}$ \\
\hline Koch et al. (2008) & 45 & ----- & 45 & 91.1 & 92.3 & 7.7 & 93.7 \\
\hline Papadaki et al. (2008) & 18 & n.n. & n.n. & 100 & n.n. & n.n. & 100 \\
\hline Ardekian et al. (2008) & 87 & ---- & 87 & 81.7 & n.n. & n.n. & n.n. \\
\hline Maresh et al. (2011) & 8 & 4 & 4 & $\begin{array}{l}\text { Total } 90 \\
\text { SMG } 100 \\
\text { PG } 100\end{array}$ & $\begin{array}{l}\text { Total } 75 \\
\text { SMG n.n. } \\
\text { PG n.n. }\end{array}$ & $\begin{array}{l}\text { Total } 25 \\
\text { SMG n.n. } \\
\text { PG n.n. }\end{array}$ & $\begin{array}{l}\text { Total } 100 \\
\text { SMG n.n. } \\
\text { PG n.n. }\end{array}$ \\
\hline Koch et al. (2011) & 153 & 153 & ----- & 94.8 & 94.8 & 5.2 & 97.8 \\
\hline Koch et al. (2012) & 99 & ----- & 99 & 89.9 & 96.8 & 10.7 & 96.8 \\
\hline Kopec et al. (2012) & 59 & 24 & 35 & $\begin{array}{l}\text { Total } 92 \\
\text { SMG n.n. } \\
\text { PG n.n. }\end{array}$ & $\begin{array}{c}\text { Total } 92 \text { (signifikant } \\
\text { 78) } \\
\text { SMG n.n. } \\
\text { PG n.n. }\end{array}$ & $\begin{array}{l}\text { n.n. } \\
\text { n.n. } \\
\text { n.n. }\end{array}$ & $\begin{array}{l}\text { Total } 98.3 \\
\text { SMG n.n. } \\
\text { PG n.n. }\end{array}$ \\
\hline Vashishta et al. (2013) & 47 & n.n. & n.n. & n.n. & Total 88 & Total 39 & Total 95.8 \\
\hline Ryan et al. (2014) & 1 & ----- & 1 & 100 & 100 & ----- & 100 \\
\hline
\end{tabular}

Legend: SMG: submandibular gland, PG: parotid gland 
vation was noted in all 82 of these patients. Patients were evaluated using a questionnaire; $50 \%$ reported swelling and $20 \%$ pain. However, the level of symptoms was low, 23.5 on a visual analogue scale (VAS) of 1-100, and scores for pain were also low (1.38 on a VAS from 1 to 10$)$. No differences were noted in relation to the different types of stenoses. A significant decrease in symptoms after treatment in comparison with the pretreatment state and a significant increase in the perceived quality of life related to the salivary glands were reported by the patients using a VAS from 1 to 100 , independently of the type of stenosis. The treatment was very well accepted by patients ${ }^{40}$.

A comprehensive treatment algorithm was also published for Stenen's duct stenosis (Fig. 2) ${ }^{50}$.

\section{Treatment failure}

If all procedures fail, ablation of gland function by surgical and chemical means may be indicated. Botulinum toxin has been successfully injected into the gland for patients with various disturbances of salivary flow. In patients with therapy-resistant ductal stenosis, repeat injection of Botulinum toxin into the gland parenchyma may arrest symptoms ${ }^{79-81}$. Duct ligation has reported to be unsuccessful in not more than $50 \%$ of cases and is therefore not a preferred procedure 121837657071 82-84.

A recent publication on 69 patients who had therapy resistant stenosis (in both glands, although the glands were not differentiated) were treated by administering alfuzosin (at $2.5 \mathrm{mg} /$ day per os) for 3-24 months. They noted "significant improvement" in $80 \%$ of patients, but no further details or side effects are described in the report, nor is any information provided about the state of the gland ${ }^{85}$.
Overall, the results in the literature show that the best success rates are achieved not with a single therapeutic modality, but rather with a combination of various treatment options. This is reflected in the comprehensive treatment algorithms published (Figs. 1, 2) ${ }^{50}$.

\section{Meta-analyses and patient acceptance of minimal sialendoscopy-guided treatment regimens}

Several meta-analyses and reviews have been published that generally confirm the effectiveness of sialendoscopyguided therapy in obstructive salivary gland diseases, but do not include any specific analyses of the management of stenoses ${ }^{86} 87$. Patient satisfaction after sialendoscopyguided treatment for obstructive salivary gland diseases has also been investigated by a few research groups. The only publication describing patient acceptance after treatment for salivary duct stenoses was mentioned earlier ${ }^{40}$. Several authors assessed patient satisfaction after sialendoscopic controlled therapy of obstructive sialadenitis, not exclusively including patients with duct stenosis 53555688 . Kroll et al., using the Short Form 36 (SF-36) questionnaire, found a high level of patient satisfaction ${ }^{53}$. Gillespie et al. using a salivary-specific standardised questionnaire (modified OHIP-14 scores) observed that the scores after treatment of cases not caused by sialolithiasis improved, but significantly less than the scores after treatment for sialolithiasis, with significantly less improvement in salivary gland-related quality of life scores ${ }^{55}$. Similar results were obtained by Aubin-Pouliot et al., who used a questionnaire designed to obtain a chronic obstructive sialadenitis score (COSS). The results showed that symptoms decreased significantly after sialendoscopy-assisted

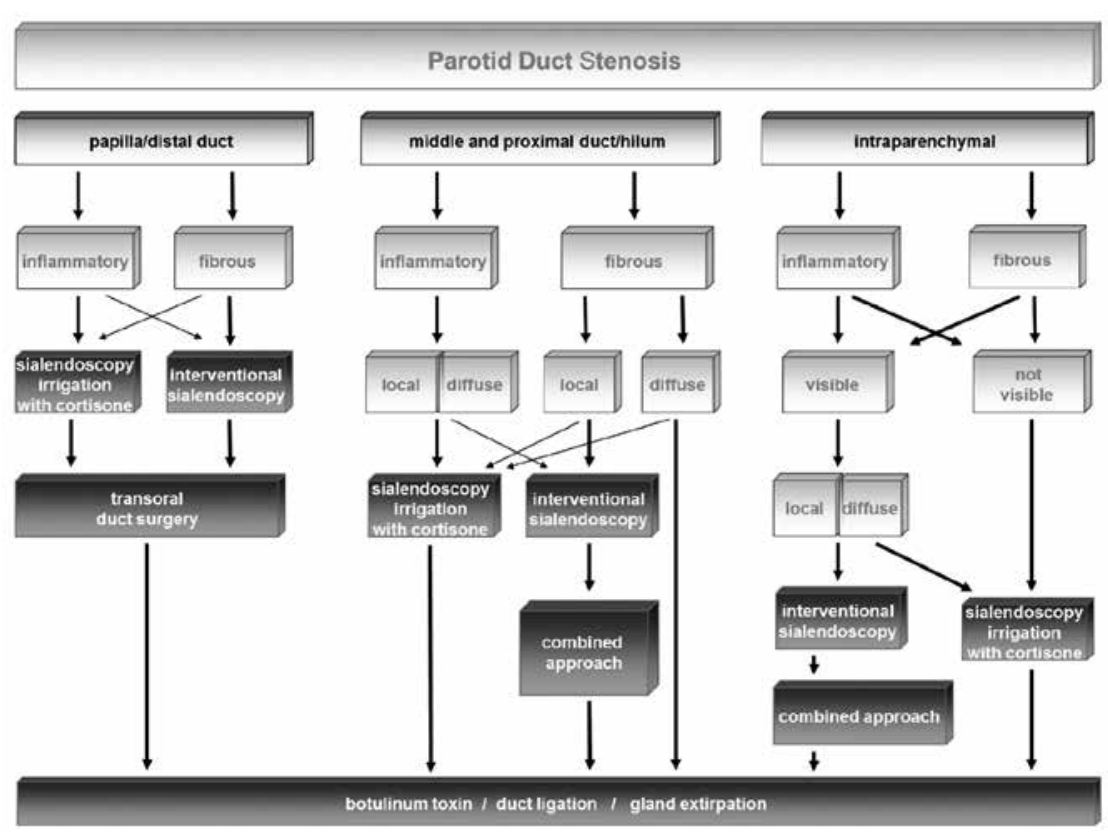

Fig. 2. Treatment algorithm for stenoses of Stensen's duct system (from Koch et al., $2009^{50}$, mod.). 
salivary duct surgery (in submandibular glands more than in parotid glands). Overall, the scores improved less after treatment for sialadenitis not caused by sialolithiasis in comparison with sialolithiasis-caused sialadenitis ${ }^{56}$. These results suggest that successful treatment for patients with gland obstruction that is not caused by sialolithiasis - or at least achieving a balanced situation during the longer-term follow-up - continues to be a challenge.

\section{Conclusions}

Ultrasound and sialendoscopy play an extremely important role in the diagnosis and treatment of salivary duct stenoses. They allow rapid, low-cost diagnosis with simultaneous planning and implementation of treatment. In general, the quality of the tissue in the stenotic region is important for deciding which treatment may be appropriate. In sialendoscopy-based treatment strategies in patients with an intact, unincised ductal system, intraductal cortisone instillation appears to have a positive effect on inflammatory and fibrotic processes. Inflammatory stenoses can often be treated by irrigation with cortisone, whereas fibrous stenoses require additional surgical treatment in the majority of cases. However, a wide range of procedures are needed to maximise the number of successful treatments. These include different methods of transoral ductal surgery in both glands.

In the submandibular duct, the location and extent of the stenosis play a very important part in the choice of treatment modality. Due to the area's good accessibility, transoral ductal surgery is the most important method. The more central the location of the stenosis, however, the more important interventional sialendoscopy becomes. In parotid duct stenoses, the concept that there are different types of stenosis in the duct has been confirmed by an extended analysis. Clear and significant differences between these types are evident. While inflammatory stenosis may be a precursor form of fibrotic stenosis, stenosis associated with webs and megaduct appears to be a completely separate type. Interventional sialendoscopy being the treatment of first choice, these significant differences between the various types of stenosis appear to support the use of different treatment strategies.

The development of minimally invasive treatment protocols and treatment algorithms (Figs. 1, 2) has made it possible to permanently relieve symptoms, with minimal morbidity, while preserving the function of the salivary glands. This is accompanied by a high level of patient acceptance for these treatment strategies. Removal of the gland is the last choice if relevant symptoms are present and the gland parenchyma is not showing a tendency to atrophy.

\section{References}

Nahlieli O, Shacham R, Yoffe B, et al. Diagnosis and treatment of strictures and kinks in salivary gland ducts. J Oral Maxillofac Surg 2001;59:484-90.
2 Marchal F, Dulguerov P, Becker M, et al. Submandibular diagnostic and interventional sialendoscopy: new procedure for ductal disorders. Ann Otol Rhinol Laryngol 2002;111:27-35.

3 Koch M, Zenk J, Bozzato A, et al. Sialoscopy in cases of unclear swelling of the major salivary glands. Otolaryngol Head Neck Surg 2005;133:863-8.

4 Ngu RK, Brown JE, Whaites EJ, et al. Salivary duct strictures: nature and incidence in benign salivary obstruction. Dentomaxillofac Radiol 2007;36:63-7.

5 Koch M, Zenk J, Iro H. Diagnostic and interventional sialoscopy in obstructive diseases of the salivary glands. HNO 2008;56:139-44.

6 Yu C, Yang C, Zheng L, et al. Endoscopic observation and strategic management of obstructive submandibular sialadenitis. J Oral Maxillofac Surg 2010;68:1770-5.

7 Lee LI, Pawar RR, Whitley S, et al. Incidence of different causes of benign obstruction of the salivary glands: retrospective analysis of 493 cases using fluoroscopy and digital subtraction sialography. Br J Oral Maxillofac Surg 2015;53:54-7.

8 Chuangqi Y, Chi Y, Lingyan Z. Sialendoscopic findings in patients with obstructive sialadenitis: long-term experience. Br J Oral Maxillofac Surg 2013;51:337-41.

9 Vashishta R, Gillespie MB. Salivary endoscopy for idiopathic chronic sialadenitis. Laryngoscope 2013;123:3016-20.

10 Koch M, Iro H, Kunzel J, et al. Diagnosis and gland-preserving minimally invasive therapy for wharton's duct stenoses. Laryngoscope 2012; 122: 552-8

11 Koch M, Iro H. Extended and treatment-oriented classification of parotid duct stenosis. Laryngoscope 2017;127:366-71.

12 Baurmash HD. Chronic recurrent parotitis: a closer look at its origin, diagnosis, and management. J Oral Maxillofac Surg 2004;62:1010-8.

13 Koch M, Iro H, Zenk J. Role of sialoscopy in the treatment of Stensen's duct strictures. Ann Otol Rhinol Laryngol 2008;117:271-8.

14 Kopec T, Szyfter W, Wierzbicka M, et al. Stenoses of the salivary ducts-sialendoscopy based diagnosis and treatment. $\mathrm{Br}$ J Oral Maxillofac Surg 2013;51:e174-7.

15 Gallo A, Benazzo M, Capaccio P, et al. Sialoendoscopy: state of the art, challenges and further perspectives. Round Table, $101^{\text {st }}$ SIO National Congress, Catania 2014. Acta Otorhinolaryngol Ital 2015;35:217-33.

16 Reddy R, White DR, Gillespie MB. Obstructive parotitis secondary to an acute masseteric bend. ORL J Otorhinolaryngol Relat Spec 2012;74:12-5.

17 Harrison JD. Causes, natural history, and incidence of salivary stones and obstructions. Otolaryngol Clin North Am 2009;42:927-47.

18 Wang S, Marchal F, Zou Z, et al. Classification and management of chronic sialadenitis of the parotid gland. J Oral Rehabil 2009;36:2-8

19 Newkirk KA, Ringel MD, Wartofsky L, et al. The role of radioactive iodine in salivary gland dysfunction. Ear Nose Throat J 2000;79:460-8.

20 Qi S, Liu X, Wang S. Sialoendoscopic and irrigation findings in chronic obstructive parotitis. Laryngoscope 2005;115:541-5.

${ }^{21}$ Koch M, Iro H, Zenk J. Sialendoscopy-based diagnosis 
and classification of parotid duct stenoses. Laryngoscope 2009;119:1696-703.

22 Chikamatsu K, Shino M, Fukuda Y, et al. Recurring bilateral parotid gland swelling: two cases of sialodochitis fibrinosa. J Laryngol Otol 2006;120:330-3.

23 Capaccio P, Cuccarini V, Ottaviani F, et al. Comparative ultrasonographic, magnetic resonance sialographic, and videoendoscopic assessment of salivary duct disorders. Ann Otol Rhinol Laryngol 2008;117:245-52.

24 Zenk J, Iro H, Klintworth N, et al. Diagnostic imaging in sialadenitis. Oral Maxillofac Surg Clin North Am 2009;21:275-92.

25 Tanaka T, Ono K, Ansai T, et al. Dynamic magnetic resonance sialography for patients with xerostomia. Oral Surg Oral Med Oral Pathol Oral Radiol Endod 2008;106:115-23.

26 Gadodia A, Seith A, Sharma R, et al. Magnetic resonance sialography using CISS and HASTE sequences in inflammatory salivary gland diseases: comparison with digital sialography. Acta Radiol 2010;51:156-63.

27 Bozzato A, Hertel V, Bumm K, et al. Salivary simulation with ascorbic acid enhances sonographic diagnosis of obstructive sialadenitis. J Clin Ultrasound 2009;37:329-32.

28 Yuasa K, Nakhyama E, Ban S, et al. Submandibular gland duct endoscopy. Diagnostic value for salivary duct disorders in comparison to conventional radiography, sialography, and ultrasonography. Oral Surg Oral Med Oral Pathol Oral Radiol Endod 1997;84:578-81.

29 Marchal F, Chossegros C, Faure F, et al. Salivary stones and stenosis. A comprehensive classification. Rev Stomatol Chir Maxillofac 2008;109:233-6.

${ }^{30}$ Christensen DR, Mashberg A, Turk MH. Correction of extreme dilatation of Stensen's duct resulting from chronic partial obstruction. J Oral Surg 1973;31:136-8.

31 Iqbal SM, Singh RR, Dewangan GL. Sailocele of Stenson's duct (a case report). J Laryngol Otol 1986;100:363-5.

32 Laudenbach P, Fain J, Canet E. [Duct cysts of the parotid. Complications of dilated Stensen's duct]. Rev Stomatol Chir Maxillofac 1990;91 Suppl 1:78-81.

33 Mandel L. The grossly dilated Stensen's duct: case reports. J Oral Maxillofac Surg 2007;65:2089-94.

34 Baurmash HD. Sialectasis of Stensen's duct with an extraoral swelling: a case report with surgical management. J Oral Maxillofac Surg 2007;65:140-3.

35 Yoon YH, Rha KS, Choi JW, et al. Sialectasis of Stensen's duct: an unusual case of recurrent cheek swelling. Eur Arch Otorhinolaryngol 2009;266:573-6.

${ }^{36}$ Lohia S, Joshi AS. Idiopathic sialectasis of the Stensen's duct treated with marsupialisation. BMJ Case Rep 2013;2013.

37 McGurk M, MacBean AD, Fan KF, et al. Endoscopically assisted operative retrieval of parotid stones. $\mathrm{Br} \mathrm{J}$ Oral Maxillofac Surg 2006;44:157-60.

38 Marchal F. A combined endoscopic and external approach for extraction of large stones with preservation of parotid and submandibular glands. Laryngoscope 2007;117:373-7.

39 Koch M, Iro H, Zenk J. Combined endoscopic-transcutaneous surgery in parotid gland sialolithiasis and other ductal diseases: reporting medium- to long-term objective and patients' subjective outcomes. Eur Arch Otorhinolaryngol 2013;270:1933-40.
40 Koch M, Kunzel J, Iro H, et al. Long-term results and subjective outcome after gland-preserving treatment in parotid duct stenosis. Laryngoscope 2014;124:1813-8.

${ }^{41}$ Brown JE. Interventional sialography and minimally invasive techniques in benign salivary gland obstruction. Semin Ultrasound CT MR 2006;27:465-75.

42 McGurk M, Escudier MP, Thomas BL, et al. A revolution in the management of obstructive salivary gland disease. Dent Update 2006;33:28-30 33-6.

43 Buckenham T, Guest P. Interventional sialography using digital imaging. Australas Radiol 1993;37:76-9.

${ }^{44}$ Roberts DN, Juman S, Hall JR, et al. Parotid duct stenosis: interventional radiology to the rescue. Ann $\mathrm{R}$ Coll Surg Engl 1995;77:444-6.

45 Brown AL, Shepherd D, Buckenham TM. Per oral balloon sialoplasty: results in the treatment of salivary duct stenosis. Cardiovasc Intervent Radiol 1997;20:337-42.

46 Waldman DL, Westesson PL, Hengerer AS. Balloon dilation of parotid duct stenosis. J Vasc Interv Radiol 1998;9:167-8.

47 Drage NA, Brown JE, Escudier MP, et al. Balloon dilatation of salivary duct strictures: report on 36 treated glands. Cardiovasc Intervent Radiol 2002;25:356-9.

48 Salerno S, Lo Casto A, Comparetto A, et al. Sialodochoplasty in the treatment of salivary-duct stricture in chronic sialoadenitis: technique and results. Radiol Med 2007;112:138-44.

49 Papadaki ME, McCain JP, Kim K, et al. Interventional sialoendoscopy: early clinical results. J Oral Maxillofac Surg 2008;66:954-62.

50 Koch M, Zenk J, Iro H. Algorithms for treatment of salivary gland obstructions. Otolaryngol Clin North Am 2009;42:1173-92.

51 Ardekian L, Shamir D, Trabelsi M, et al. Chronic obstructive parotitis due to strictures of Stenson's duct - our treatment experience with sialoendoscopy. J Oral Maxillofac Surg 2010;68:83-7.

52 Koch M, Iro H, Klintworth N, et al. Results of minimally invasive gland-preserving treatment in different types of parotid duct stenosis. Arch Otolaryngol Head Neck Surg 2012;138:804-10.

53 Kroll T, Finkensieper M, Sharma SJ, et al. Short-term outcome and patient satisfaction after sialendoscopy. Eur Arch Otorhinolaryngol 2013;270:2939-45.

54 Pace CG, Hwang KG, Papadaki ME, et al. Sialadenitis without sialolithiasis treated by sialendoscopy. J Oral Maxillofac Surg 2015;73:1748-52.

55 Gillespie MB, O'Connell BP, Rawl JW, et al. Clinical and quality-of-life outcomes following gland-preserving surgery for chronic sialadenitis. Laryngoscope 2015;125:1340-4.

56 Aubin-Pouliot A, Delagnes EA, Chang JL, et al. Sialendoscopy-assisted surgery and the chronic obstructive sialadenitis symptoms questionnaire: a prospective study. Laryngoscope 2016;126:1343-8.

57 Capaccio P, Torretta S, Di Pasquale D, et al. The role of interventional sialendoscopy and intraductal steroid therapy in patients with recurrent sine causa sialadenitis: a prospective cross-sectional study. Clin Otolaryngol 2017;42:148-55.

58 Maresh A, Kutler DI, Kacker A. Sialoendoscopy in the diag- 
nosis and management of obstructive sialadenitis. Laryngoscope 2011;121:495-500.

59 Labrunie G, Lair J, Touzet C. [Bypass whartonostomy (author's transl)]. Rev Stomatol Chir Maxillofac 1981;82:70-5.

60 Rontal M, Rontal E. The use of sialodochoplasty in the treatment of benign inflammatory obstructive submandibular gland disease. Laryngoscope 1987;97:1417-21.

61 Karas ND. Surgery of the salivary ducts. Atlas Oral Maxillofac Surg Clin North Am 1998;6:99-116.

${ }^{62}$ Mandel L, Kaynar A. Surgical bypass of submandibular duct stricture. Oral Surg Oral Med Oral Pathol Oral Radiol Endod 1999;88:532-3.

${ }_{63}$ Zenk J, Constantinidis J, Al-Kadah B, et al. Transoral removal of submandibular stones. Arch Otolaryngol Head Neck Surg 2001;127:432-6.

${ }^{64}$ McGurk M. Surgical release of a stone from the hilum of the submandibular gland: a technique note. Int J Oral Maxillofac Surg 2005;34:208-10.

${ }_{65}$ Motamed M, Laugharne D, Bradley PJ. Management of chronic parotitis: a review. J Laryngol Otol 2003;117:521-6.

66 Nahlieli O, Bar T, Shacham R, et al. Management of chronic recurrent parotitis: current therapy. J Oral Maxillofac Surg 2004;62:1150-5.

67 Galili D, Marmary Y. Juvenile recurrent parotitis: clinicoradiologic follow-up study and the beneficial effect of sialography. Oral Surg Oral Med Oral Pathol 1986;61:550-6.

68 Bowling DM, Ferry G, Rauch SD, et al. Intraductal tetracycline therapy for the treatment of chronic recurrent parotitis. Ear Nose Throat J 1994;73:262-74.

69 Antoniades D, Harrison JD, Epivatianos A, et al. Treatment of chronic sialadenitis by intraductal penicillin or saline. $\mathrm{J}$ Oral Maxillofac Surg 2004;62:431-4.

70 Munzel M, Meister P. [On the ligation of Stenon's duct in chronic-recurrent parotitis (author's transl)]. Laryngologie Rhinologie Otologie 1977;56:902-6.

71 Nichols RD. Surgical treatment of chronic suppurative parotitis. A critical review. Laryngoscope 1977;87:2066-81.

72 Cohen D, Gatt N, Olschwang D, et al. Surgery for prolonged parotid duct obstruction: a case report. Otolaryngol Head Neck Surg 2003;128:753-4.

73 O'Brien CJ, Murrant NJ. Surgical management of chronic parotitis. Head Neck 1993;15:445-9.

74 Sadeghi N, Black MJ, Frenkiel S. Parotidectomy for the treatment of chronic recurrent parotitis. J Otolaryngol 1996;25:305-7.
75 Moody AB, Avery CM, Walsh S, et al. Surgical management of chronic parotid disease. Br J Oral Maxillofac Surg 2000;38:620-22.

76 Amin MA, Bailey BM, Patel SR. Clinical and radiological evidence to support superficial parotidectomy as the treatment of choice for chronic parotid sialadenitis: a retrospective study. Br J Oral Maxillofac Surg 2001;39:348-52.

77 Patel RS, Low TH, Gao K, et al. Clinical outcome after surgery for 75 patients with parotid sialadenitis. Laryngoscope 2007;117:644-7.

78 Ryan WR, Chang JL, Eisele DW. Surgeon-performed ultrasound and transfacial sialoendoscopy for complete parotid duct stenosis. Laryngoscope 2014;124:418-20.

79 Ellies M, Gottstein U, Rohrbach-Volland S, et al. Reduction of salivary flow with botulinum toxin: extended report on 33 patients with drooling, salivary fistulas, and sialadenitis. Laryngoscope 2004;114:1856-60.

${ }^{80}$ Capaccio P, Torretta S, Osio M, et al. Botulinum toxin therapy: a tempting tool in the management of salivary secretory disorders. Am J Otolaryngol 2008;29:333-8.

81 Kruegel J, Winterhoff J, Koehler S, et al. Botulinum toxin: A noninvasive option for the symptomatic treatment of salivary gland stenosis - a case report. Head Neck 2010;32:959-63.

82 Diamant H. Ligation of the parotid duct in chronic recurrent parotitis. Acta Otolaryngol 1958;49:375-80.

83 Morgan WR. Parotid duct ligation and tympanic neurectomy in chronic recurrent parotiditis. Arch Otolaryngol 1973;98:179-82.

${ }^{84}$ Harrison JD, Fouad HM, Garrett JR. The effects of ductal obstruction on the acinar cells of the parotid of cat. Arch Oral Biol 2000;45:945-9.

85 Guerre A, Hartl DM, Katz P. [Alpha-1-blockers (alfuzosin) for obstructive salivary gland diseases]. Rev Stomatol Chir Maxillofac 2010;111:135-9.

86 Strychowsky JE, Sommer DD, Gupta MK, et al. Sialendoscopy for the management of obstructive salivary gland disease: a systematic review and meta-analysis. Arch Otolaryngol Head Neck Surg 2012;138:541-7.

87 Atienza G, Lopez-Cedrun JL. Management of obstructive salivary disorders by sialendoscopy: a systematic review. $\mathrm{Br}$ J Oral Maxillofac Surg 2015;53:507-19.

88 Meier BA, Holst R, Schousboe LP. Patient-perceived benefit of sialendoscopy as measured by the Glasgow Benefit Inventory. Laryngoscope 2015;125:1874-8.

Address for correspondence: Michael Koch, Department of Otorhinolaryngology, Head and Neck Surgery Friedrich Alexander University of Erlangen-Nuremberg, Waldstrasse 1 D-91054 Erlangen, Germany. Tel. +499131 85 43839. Fax +499131 85 33833. E-mail: Michael.Koch@uk-erlangen.de 